OPEN ACCESS

Edited by:

Felix Kwabena Donkor

University of South Africa, South Africa

Reviewed by:

Viswanathan Pozhamkandath

Karthiayani,

Amrita Vishwa Vidyapeetham, India

Tlou Raphela,

University of the Free State,

South Africa

${ }^{*}$ Correspondence:

Naudé Malan

nmalan@uj.ac.za

orcid.org/0000-0002-6529-1983

Specialty section:

This article was submitted to Land, Livelihoods and Food Security,

a section of the journal

Frontiers in Sustainable Food Systems

Received: 04 May 2021

Accepted: 30 August 2021

Published: 24 September 2021

Citation:

Malan N (2021) Steering the Nexus:

iZindaba Zokudla and Governing for

Sustainability.

Front. Sustain. Food Syst. 5:705045.

doi: 10.3389/fsufs. 2021.705045

\section{Steering the Nexus: iZindaba Zokudla and Governing for Sustainability}

\author{
Naudé Malan* \\ Member of Council of the Agricultural Research Council of South Africa, University of Johannesburg, Johannesburg, \\ South Africa
}

"iZindaba Zokudla" means we talk about the food that we eat. iZindaba Zokudla is a public innovation lab that uses stakeholder-engagement methods to create "opportunities for urban agriculture in a sustainable food system." iZindaba Zokudla is presented as an extra-institutional means to govern the water, land, energy, and waste nexus. This reflective essay critically describes iZindaba Zokudla and applies this to the design of institutional steering mechanisms to govern the food, water, land, and energy nexus towards sustainability. Governance is an intersubjective and interactive process between the subjects of governance and governance itself. Sustainability, as an interactive process, implies the creation of autocatalytic and symbiotic communities in society that integrates diverse actors and stakeholders, inclusive of scientific and lay actors, and ecosystems. iZindaba Zokudla is a means to govern and create such communities, and this article describes and reflects on how iZindaba Zokudla has created and managed such symbiotic communities or autocatalytic networks in the food system. The article generalises how the activities conducted in iZindaba Zokudla can be used to govern the water, land, energy, and waste nexus for sustainability. The article shows how iZindaba Zokudla has realised a progressive governance through the facilitation of its Farmers' Lab and website; how it has created opportunities for participation; and how it enables critical reflection in society.

\footnotetext{
Keywords: stakeholder engagement (SE), governance (ESG), communities of practise (COP), agriculture transformation, public innovation lab
}

\section{INTRODUCTION: IZINDABA ZOKUDLA AS EXTRA-INSTITUTIONAL GOVERNANCE}

iZindaba Zokudla ${ }^{1}$ is a multi-stakeholder engagement project that aims to create opportunities for urban agriculture in a sustainable food system. iZindaba Zokudla emerged from a research project in participatory technology design (Malan and Campbell, 2014; Campbell and Malan, 2018; Malan, 2020a). The NGOs REOS Partners and TransForum (REOS Partners, and TransForum, 2011) and the South African Food Lab introduced the author to food systems thinking and TransForum's multi-stakeholder engagement methodology accommodating public, business, and civil society interests (Regeer et al., 2011; Van Latesteijn and Andeweg, 2011). TransForum's approach is to build sustainable business by linking with "all relevant stakeholders" (Regeer et al., 2011:27). These small teams include entrepreneurs, welfare, and public sector representatives, a process monitor, and other stakeholders. iZindaba Zokudla follows this, albeit by mobilising stakeholders in a social

\footnotetext{
${ }^{1}$ In isiZulu this correctly means "the court of the Chief where we discuss the food that we eat together."
} 
lab (Hassan, 2014) as an open participatory event (the Farmers' $\mathrm{Lab}$ ) wherefrom groups may be mobilised for enterprise creation and activism in the food system.

The water, land, energy, and waste nexus (hereafter "the nexus") overlaps with the food system. A sustainable food system will transform the current system and manage it within its biological and physical limits, and the regenerative potential inherent in its resources. The trade of food by "enterprises" however creates opportunities for sustainability as enterprises can innovate and develop sustainable products and services. Economic activity and businesses are "brokers between producers and consumers [that can] create new socioecological relations" (Pereira et al., 2020: 1327) and these "Entrepreneuring" (Bruton et al., 2013; Tobias et al., 2013; Lynde, 2020) or "institutional entrepreneurship" (Sidibé et al., 2018: 95) or "infrastructuring" (Nogueira et al., 2020) opportunities are a form of governance that can create sustainable enterprises and transform the food system. iZindaba Zokudla is an open, voluntary forum located in academia and civil society that aims at creating enterprises based-on new relationships between actorentrepreneurs/activists (those who act) and stakeholders, who have an interest in the sustainability of such enterprises.

iZindaba Zokudla contributes to sustainability by creating opportunities for public deliberation on a sustainable food system. This manages and governs the system, but the Lab attracts actors and stakeholders with a clear interest in a low external input agriculture (Malan, 2015: 55). These deliberative choices influence others, and creates overarching narratives for action, and this has moved many towards collaborating and adopting sustainable practises. This article distils the experience of the "convener" of this forum to identify how such a forum or social lab can help govern the water, land, energy and waste nexus towards sustainability.

The author hosted a series of workshops in 2013 to "embed" the participatory technology design project in the local community in Soweto, Johannesburg. This "assembly" led to the creation of iZindaba Zokudla and the Farmers' Lab and aimed at creating a strategic plan for urban agriculture in Soweto, Johannesburg (Malan, 2015). iZindaba Zokudla's Farmers' Lab should be understood as a form of a "public innovation lab" (McGann et al., 2018, 2019) or a "social lab" (Hassan, 2014) that uses social methodologies, and now digital methods (Williamson, 2015) to achieve its ends.

iZindaba Zokudla's Farmers' Lab (The "Lab") has amongst others instituted a system of referral and facilitation to key entities in the University of Johannesburg, civil society, state, and business that assist emerging entrepreneurs. On the 13th of May 2017 it hosted activists from the African Centre for Biodiversity, The Department of Agriculture Forestry and Fisheries and Bioversity International that discussed the creation of seed libraries. Later, on the 5th of August 2017, a leading activist used the Lab to organise farmers to participate in a public information session organised by Parliament on new seed Bills (Rousell, 2017). This assisted a submission to Parliament on the Bills, but two aspects of this organising deserve mention. The activist mentioned later formed an agricultural incubator with other activists and entrepreneurs (which is linked to the activities of iZindaba Zokudla) and another farmer arrived at the Farmers' Lab on the 19th of August 2017 with more than 30 different kinds of indigenous seeds that he catalogues in a seed library, which forms part of his farming enterprise. These actors created sustainable activities with, through and alongside iZindaba Zokudla, and this is described in this article.

The methods used in the Lab enables local actors to coalesce and draw on the opportunities and resources amongst themselves (Malan, 2020c). The Lab is an "omnibus" event that lowers the opportunity cost of pitching and developing a new enterprise, facilitates access to farmers for researchers and business incubators, and allows farmers to network and build relationships with a broad range of stakeholders, including activists, and vice-versa. The Lab has also facilitated the "launch" of both the Khula! app (http://www.khula.co.za/) and the uptake of aparate.co. amongst farmers in Soweto. iZindaba Zokudla hosted the Slow Food Soweto Eat-Ins (see Malan, 2020c), food festivals that vividly and publicly illustrate the viability of a sustainable food system. The Lab was active from the 16th of May, 2015, until the 14th of March, 2020 when Covid19 regulations temporarily prohibited face-to-face gatherings. The last workshop attracted more than 400 participants, and tested financial products for new and small-holder farmers, and indigenous vegetables and seeds, amongst others ${ }^{2}$. During 2020 preparatory work was done to build the iZindabazokudla.com website as digital means to manage virtual "Communities of Practise" as an entrepreneurship development strategy (Wenger, 1998; Malan and van der Walt, 2019) that is only briefly described in this article.

\section{GOVERNANCE IN A PUBLIC INNOVATION LAB}

Ostrom (1990) reminds us that actors in common-property regimes develop "shared norms and patterns of reciprocity" and "social capital with which they can build institutional arrangements" (1990: 184) to govern the commons. Existing institutional structures however, are (constantly) transformed by the supply of new institutional arrangements. This "competitive" supply of new arrangements leads the development of new institutional and governance regimes which is key in successful governance.

Social labs create "infrastructuring" (Nogueira et al., 2020), architecting (Lynde, 2020: 3) or "structuration" (Gebreyes, 2018: 130) opportunities to renegotiate the structures wherein action takes place, akin to the development of new governance arrangements. iZindaba Zokudla, as a "social lab," enables actors and stakeholders to shape systems and incorporate diverse influences in the food system as they realise their own projects. Nogueira et al. (2020: 3) emphasise that “... infrastructures carry a system of offerings (e.g., people, objects, environments, messages, and services) and affordances that standardise the circulation and allocation of resources, as well as how the infrastructure is used." They emphasise that a public innovation

${ }^{2}$ See: https://www.facebook.com/IzindabaZokudla/posts/2593612467524472. 
lab offers an opportunity to renegotiate and "democratise the processes of determining how resources should be allocated and mobilised" and change what these "offerings afford users to do."

The opportunity to "infrastructure" society or governance creates an interactive and subjective relationship between actors and stakeholders. As they structure or "infrastructure" systems, enterprises, products, and governance arrangements, they themselves get shaped by these very same arrangements. This occurs in a very peculiar way in a public innovation lab. A "public innovation lab" is "an experimental R\&D lab for social and public problems, located in the interstitial borderlands between sectors, fields, and disciplinary methodologies" (Williamson, 2015: 256). A public innovation lab is important as it can produce "new methods for making sense of social phenomena ... redefining the way the ... world works, designing methods to measure it, and producing policy products and recommendations to modify it" (Williamson, 2015: 267).

A public innovation lab creates the subject of governance in a very peculiar way. A "Lab" shapes subjects to become "governable participants in emerging strategies, techniques, and methods of digital governance" (Williamson, 2015: 267). iZindaba Zokudla influences governance through the creation of subjects of governance-or entrepreneurs who influence the food system through their activities in the market. An intersubjective conception of governance allows us to understand how actors outside structures of power and in society influence governance itself. Below we examine what is at stake when governance is intersubjective.

\section{GOVERNANCE AS INTERSUBJECTIVE}

Intersubjectivity stands in some contrast to a hard-command and control-conception of governance. The South African King IV report (IoD, 2016) warns against following such "mindless rules” (2016: 36). It invites intersubjectivity (IoD, 2016: 4) as a "stakeholder-inclusive" approach, that is a "party to all sources of value" created "for itself, and others" (2016: 25). Significantly, it proposes "Sustainability" as "an interdependent relationship between the organisation and its stakeholders, and the organisation's ability to create value for itself depends on its ability to create value for others" (IoD, 2016: 23).

The philosophical history of governance as an intersubjective endeavour is reconstructed by Thomas Lemke from published interviews of the philosopher Michel Foucault (1926-1984). Governance and "governmentality"-as governing "self and others"-stems from constitutionalism and the demise of the old European feudal system. New states determined, and was determined by, the creation of a new "subject" of the state, the citizen. Governance is tied up with "the modern sovereign state and the modern autonomous individual [who] co-determine each other's emergence" (Lemke, 2007: 44, Lemke, 2000: 3). "Hence we can speak of the economy as an open economic domain that is created only by incessant social intervention" (Lemke, 2000: 196). Governance consequently begs the question of "the conditions of a consensus or the prerequisites of acceptance” (Lemke, 2002: 54).
When we govern and are governed, we may acquiesce or innovate. Governance allows actors opportunities to constantly re-negotiate, with others, the activities they are performing. The idea of "infrastructuring" as means to recreate systems, opportunities and current paths of activity converges with an intersubjective governance. A public innovation lab creates the conditions for such "infrastructuring" to take place. The effects of this are clearly felt outside the lab, in society, and in the changed behaviour of actors and systems.

\section{GOVERNANCE AS "INFRASTRUCTURING”}

In South Africa the background contours of the market are shaped not completely by free-market principles, but also by an affirmative and race-based strategy (Broad-Based Black Economic Empowerment Act No. 25899, 2004). Formal property rights are also under pressure in South Africa (Minister of Public Works, 2020), suggesting an informal and indeterminable system of access to land is emerging. Suchá et al. (2020), in a study of urban agriculture in Soweto, highlights that informal "perceived" tenure security is as effective, if not more effective, than formal tenure (2020:6) in stimulating investments on land. Farmers build fences in order to enhance tenure security: "Fencing represents physical protection against thefts which can also be considered as a tenure-building strategy, even in cases where farmers do not hold any land rights ... and which might encourage farmers to enhance their investment" (2020:4). In a context of fluid property rights, governance will thus be affected by this ability of actors to "infrastructure" (Gebreyes, 2018; Nogueira et al., 2020) arrangements or "produce urban agriculture" (Siegner et al., 2020) through their actions.

"Infrastructuring" allows actors, including academics, to "produce" systems to their advantage. Siegner et al. (2020) note the "multifunctional" benefits of urban agriculture that creates incentives to "produce" it in different ways. Siegner et al. (2020: 567) contrast the "social and ecological benefits" of urban agriculture with the "productivist" way commercial agriculture is measured. Urban agriculture produce (and thus "infrastructures") social and ecological effects that may be more important than mere food production.

A situation where urban agriculture's potential is not met, would likely lead to "infrastructuring" activities to promote the policy and public support available for urban agriculture. To govern the nexus for sustainability, a new set of opportunities have to be "infrastructured" so actors can "produce" specific benefits like health or sustainability in the way they take action on food, water, land, energy, and waste. This emergent theory of social change, which has implications for the formal regulation of society, indicates actors, and stakeholders will exploit opportunities for engagement and change. A public innovation lab is suggestive of a new paradigm for governance, closely based-on engagement opportunities and methodologies, that can align self-interest with the interests of others. This intersubjective contest can govern for "sustainability." 


\section{GOVERNANCE FOR SUSTAINABILITY}

Sustainability as "meeting the needs of the present without compromising the ability of future generations to meet their own needs" (WCED, 1987) is conducive to a self-regulating system that meets human needs through the protection of nature. This implies "deliberate self-regulation, from personal action to geoengineering schemes" (Lenton and Latour, 2018: 1,067), including "large scale mobilisation of scientists, activists, and citizens" to link the agency of nature with social and economic systems, so it can continuously provide food, fibre, fuel, minerals, and all other resources for humans. "The challenge is to support diverse autocatalytic networks of human agents that can propel transformations towards goals such as sustainable energy, fuelling the efficient recycling of resources" (Lenton and Latour, 2018: 1,067). Sustainability will emerge if these networks can "infrastructure" actors and stakeholders, society, and enterprises to create a self-reproducing system based-on ecological limits.

Governance for sustainability ought to ensure ecosystem functioning for human life, and this implies the following (Lenton and Latour, 2018: 1,067):

- Recycling and feedback loops and distributed control in industry and circular business models that enable "autocatalytic" networks to engage directly with the governance and transformation of such processes;

- Long-term structures that operationalise the above, including the establishment of "sensors" to release information on planetary processes and limitations; and,

- Networks and relationships need to be built amongst humans, to create the requisite density amongst people for autocatalytic communities to emerge.

In the food system, "organic" or "local" food may be consistent with the creation of a sustainable food system. This framing must be consistent from the food as produce and product, downstream to production methods and wastes, and upstream to consumers and distribution and retail systems. This value chain, or peculiar network of scientists, farmers, citizens etc. has to be coordinated to consistently "produce" sustainability at the system, enterprise, or product levels.

Sensors would have to be "animated" to give the network purpose and direction. Social capital would have to "glue" it together. Spaces and places need to be found for people to organise, deliberate and plan. Media, technologies, and activities need to operationalise these plans. Malan (2020c: 34) describes how Slow Food's slogan of "Good, Clean and Fair" has animated a whole set-or "cascade" - of activities, from farmers' markets to public conferences, and this is consistent with the seed example above. This network that "created" it, may have been transient, but echoes Jensen and Orfila’s (2021: 565) description of a symbiotic community in the food system. This community aims at:

Creating a symbiosis between communities officially classified as multiply deprived, underutilised local assets and infrastructure, and the activities of those operating within the local food sector that are potential sources of critical resources [and this] presents opportunities for myriad beneficial food production, processing, distribution and education hubs.

Recent discussions of the governance of the South African food system towards sustainability and/or food security is consistent with how an autocatalytic network or symbiotic community realises sustainability. The South African food system produces "alarmingly high levels of food waste"; "is a major source of greenhouse gas emissions"; and "depends on several other systems" to function (Battersby et al., 2015: 47; 48). The "broader food system sustainability challenges intersect with a number of structural food system challenges" (Battersby et al., 2015: 48). In this regard, practises such as maintenance of agro-ecology (Siegner et al., 2020), food sovereignty (McMichael, 2014), and organic production (Battersby et al., 2015: 52; Csortan et al., 2020), have been suggested as a frame to guide action, and these choices will influence how the community, network or political activity will be structured and animated.

Siegner et al. (2020: 581; see also Jensen and Orfila, 2021: 564) equates agroecology with "synergistic social, cultural and ecological dimensions." This has consistency with an approach that understands how people "navigate" (Battersby, 2012: 155) their own foodscapes and their "households' actual food geographies" (Joubert et al., 2018: 147). This suggests governance for sustainability needs to frame the governance of the nexus as amenable to change by actors' own volition.

\section{GOVERNANCE AND SUSTAINABILITY: ANIMATION, POLYCENTRIC GOVERNANCE, AND FACILITATION}

"Governance" as the creation and enforcement of rules and regulations is often accompanied by a vision of an ideal end state, and this creates narratives that frame an issue in a particular way. The idea of "food security," defined as the availability, accessibility and acceptability (a.o.) of food at "all times" leads to a welfarist or "assistencialist" conception of governance (Clayes, 2015; Haysom, 2015). This allocates power to specific actors like relief agencies and reproduces hierarchical systems. Sustainability however demands that we transform them.

A public innovation lab allows alternative frames or narratives to emerge. The idea that actors should "draw on resources" (Malan, 2020c) in a lab and combine them (Malan, 2020b) in their own projects' frames action differently than a welfare frame. This identifies the autonomous actions of entrepreneurs-or local actors-as key to change. Framing sustainability as amenable to local action by autocatalytic networks, moves beyond "open and transparent engagement" (Pereira, 2014: 39; Battersby et al., 2015: 63) and mere "mechanisms for stakeholder involvement" (Roosendaal et al., 2020: 25). We must enable actors to practise a form of "bricolage" in building up such narratives and networks so they can link diverse issues (Sidibé et al., 2018: 96). To operationalise environmental issues, and address the structural constraints underpinning them, such a lab would need to integrate multiple cross-cutting perspectives holistically (Candel, 2018: 105). This enables a polycentric governance that integrates 
multiple perspectives (Termeer et al., 2018: 86) that would create a social division of labour appropriate for the issue at hand. This flexibility would be hard to achieve without deep engagement with people.

To allow governance to adapt and address new or novel issues and changes (Roosendaal et al., 2020: 110; Termeer et al., 2018: 86) it needs to "improvise" groups in society that cross-cut current divisions, so that they can produce "symbiotic" enterprises, nested in activist, educational, and other communities. These can create economic and social benefits based-on the conservation and productivity of the environment.

Pereira and Drimie (2016: 27, 29) bring this to bear on the construction of "a strong durable global food movement" and "... institutions that can convene and facilitate multisectoral action." Transitions would need existing actors to coordinate with new opportunities and actors, and they may need a "safe space" (Pereira et al., 2015) like a public innovation lab to do so. It may well be an essential part of governing for sustainability.

Labs' ability to "infrastructure" new means to govern depends upon the design of the methodology of interaction. Regeer et al. (2011: 208) presents workshop methods as tools "for Alliance Building" and "for Co-creation" and "for Embedding and Alignment" as part of a "connected values" approach. Pereira (2021: 2), pertinently, advocates for a hybrid of the "M $\tilde{\alpha}$ noa" method and the "Three Horizons" framework which helps in "considering the possible pathways and points of intervention that link the present to our future visions." Methods have clear networked and systemic and governance effects through the way they create communities amongst peers that would further a progressive agenda.

Digital governance utilises social media as facilitatory means, and below we describe some of these. "Inscription devices" (Williamson, 2015: 259) enable the digital creation of networks: "Through the hashtag, the histories and methods of various different organisations and actors ... are hooked up, interwoven with one another, and stabilised as a coherent body of knowledge and practises." An "inscription device," in stabilising reality, indicates how to commence with the creation of an autocatalytic network. Social media offers opportunities for "self-regulation ...distinct from the corporate platforms" and this is one of "the great democratic possibilities of the social media age" (Flew, 2020: 2). The hashtag suggests broad solidarity and mobilisation opportunities is possible through a "platforming intersectionality" (Christian et al., 2020: 1) which could create "entrepreneurial solidarities" (Soriano and Cabañes, 2020). The "ability to affect and be affected" (Carlson and Frazer, 2020: 2) through peer-to-peer networks and movements is an instance of intersubjective governance.

\section{SOURCES OF KNOWLEDGE FOR THIS CASE STUDY}

This reflective essay is based on a long-term open-ended research programme, based-on participant observation and reflection, by an activist-academic, of the change processes that occur in the food system. The author organises and promotes the Lab not as a neutral actor but as a committed activist-academic. The author's leadership position in the project is illustrative of a "transformative capacity" and "advanced forms of leadership, resources, and skills; target agenda setting, policy planning, implementation and enforcement, and longterm embodiment" (Termeer et al., 2018: 87). The content the author creates includes the development of an editorial and report on each event, the development of an unpublished manuscript, a fieldwork diary, additional writings as they appear in third-party publications (including websites) and the information available on the iZindaba Zokudla Facebook page (https://www.facebook.com/IZindabaZokudla) and the website iZindabazokudla.com.

This article draws on the information mentioned above, supplemented by observations inside, and outside the lab, including stakeholders and how they approach the author in order to gain access to the farmers and entrepreneurs who frequent the Labs. The Labs attract between 100 and 400 participants per event, and this indicates the popularity and need for such an intermediary institution between actors and stakeholders. The Labs' Agenda and the important "announcement hour" have mobilised NGOs, Academics and researchers, local and other businesses, journalists, and others and they actively uses the Labs to further their own ends, albeit in a public arena. Actors have made available opportunities in these labs, and these include offers and requests for land, for training, for new technology and new business opportunities. Recording and diarising these events enables the author to comment on a wide range of issues relevant to food systems change, and in this article these insights are generalised to governance and the idea that we could govern through a public innovation lab.

The descriptions in this article derive from public activities and some persons may be identifiable through these. However, descriptions are abstracted to protect their identity, and also to focus the discussion on key theoretical issues and not on persons and circumstances. This approach has been approved through an institutional review by the author's host institution (Humanities ethical clearance no. REC-01-131-2020). The tone of this essay is therefore abstract, reflective and argumentative, in order to reflect, and allow others to reflect, on governance.

\section{IZINDABA ZOKUDLA AS MEANS TO GOVERN THE NEXUS}

Three key themes cross-cut all the governance issues identified above. After I present the case study background below, I move to reflect on how facilitation in the Farmers' Lab proceeds, and this includes reflection on both the open-access events, and the digital or virtual means that are available. I then focus on how people participate in the Farmers Lab, the website, and Facebook. This enables a lab to reflect on society and is described in order to conclude the essay. This thick description allows us to comment on how progressive governance of the nexus can proceed. 


\section{BACKGROUND: WHAT IS IZINDABA ZOKUDLA?}

iZindaba Zokudla's Farmers Lab is held mostly once a month on the Soweto Campus of the University of Johannesburg. The Virtual Lab is a webinar-type programme that presents panel discussions on key topics in the food system-some relevant to the Facebook Groups on the Facebook Page. The project is developing outreach programmes in the School of Management at the University of Johannesburg for future implementation.

The Farmers' Lab exemplifies the character of iZindaba Zokudla and was created to collapse action research methodology into an event. Action research depends upon small-group interaction (Burns, 2012: 98). However, agriculture is mainly a market-based activity, with change occurring outside in the market context. This allows synergies to emerge in society made by individual entrepreneurs. Hence, it is necessary to implement methods not amongst small groups, but amongst individuals in society.

The Farmers' Lab is a "festival" type of event implemented in a food system that laboured under many centuries of colonialism and apartheid and is permeated by large agricultural producers with certain hegemony over the food system (Cochet et al., 2015) that would maintain their position in the food system at the expense of innovation (Van der Ploeg, 2016) and are likely to exploit emerging producers. Small urban producers are located in "townships" where there is a dearth of entrepreneurial activity (Mahajan, 2014) but significant attempts to build a new society. The Farmers' Lab-open to these influences-is an "assembly" and not a well-defined "association" or "organisation." This open bordered assembly underscores the need to make deliberate methodological choices in how engagement will take place.

The genesis of the Lab stems from "workshops" that were conducted with stakeholders locally and globally (11 March 2014) through a webinar, in order to first establish a farmers' market. Four attempts ended in failure, but this motivated others to create the Soweto Market Place (https://www.facebook.com/ thesowetomarketplace/). After this, the Farmers' Lab was created, and the pressure the author experienced from diverse entities outside the University to realise this, suggests such a lab has effects in the "infrastructuring" activities of actors.

The referral system established at the UJ that links to appropriate entities in the University, suggests a form of polycentric governance is necessary for effective governance of the nexus. Such an ecosystem is facilitated by organising the Lab not as a membership association, but as an open assembly of persons. This invites actors to freely engage with others, and this freedom to create associations can achieve progressive effects through dedicated facilitation methodologies.

\section{FACILITATION}

iZindaba Zokudla affords emergent entrepreneurs' access to two main fora, the Farmers' Lab and the Virtual Lab. The Virtual Lab aims to organise emergent producers into communities of practise (Wenger, 1998). This form of group organising conceptualises control over the group as stemming from inside the group. Groups can develop their identity through own materials and profiles and "mini-documentaries" on the website, which forms the basis for future collaboration in outreach programmes. Actors will be able to develop a "reputation" alongside their identity profiles which will enable actors to self-select whom they want to work with. This leads to less hierarchical group characteristics that is important for the autonomy of entrepreneurs.

A community of practise aims at the maintenance of the group, so the group can mediate economic entry-establishing an enterprise or trading-amongst themselves. To protect such a group from enrolment into vested interests, we need to afford actors in these groups multiple paths of development, so they can by-pass hegemonic interests. Malan and van der Walt (2019: 15-16) set out how this may take place.

- Group formation has to take place in a plural context blending real-life sessions and digital activities. Themes or narratives create groups identities, and specific aims, like a "local" food system;

- Groups need to self-realise themselves through knowledge, communication and solidarity, and this will enable them to develop their interests. A flexible ecosystem enables people to make their own decisions on production supported by the opportunities available in society;

- A plural context fostered by alternative knowledges and practises enables innovation and is necessary to guard against exploitation and domination. Sustainable production models, like circular enterprises, offers clear advantages over current production methods. When alternatives are offered to farmers, new patterns emerge in society;

- A community of practise is a value chain, and this approximates an autocatalytic network or symbiotic community and has potential as a steering mechanism of economic growth. Value chains can now be controlled and steered amongst peers, and alternative and experimental systems of production can be set-up or imagined inside the safety of a group; and,

- The above will create a new ecosystem that approximates a sustainable food system by allowing groups to re-define an economic sector or activity, albeit at the local scale.

The above will enable emergent actors to create and control the networks within which they act. This creates a broad context wherein people can participate. To realise such a system of innovation we need to design the opportunities which structure how actors participate in iZindaba Zokudla’s Labs.

\section{PARTICIPATION}

The open access organising that takes place in the Farmers' Lab on the University of Johannesburg Soweto Campus, and the digital means afforded to them, structures actors' activities as it controls the proceedings in the Labs. These activities create narratives to structure action, develop methodologies 
of engagement, and this allows entrepreneurs to form their own networks.

\section{The Lab and Its Agenda}

The Lab is structured in ways that were developed by trial and error but is designed so that anyone can participate and influence the proceedings on the day. To do so, the following features are highlighted:

- The Lab, to create a sense of belonging, opens with a song, a poem or a prayer, as is common practise amongst local community-based organisations;

- The Lab is advertised through a Short Message System on mobile phones that is able to reach those without internet connectivity. This is shared further on several WhatsApp groups by the author and recipients;

- An Editorial developed by the facilitator sets the tone in each event and enables control over proceedings through narratives that frame key issues in particular ways to enable strategic issues to be identified and deliberated upon;

- An announcement hour which allows anyone to take the stage and pitch or advertise their enterprise or products or activism. This takes up the bulk of the day. Actors use this opportunity to find new clients and markets, and to create groups amongst themselves. These pitching sessions are immediately photographed and posted, and are retrievable on Facebook;

- The theme of the day is often dealt with by inviting scientific and local experts to give a lecture on a given topic. This has ranged from Mycotoxins in the food chain, to pollution in soils, to organic or permaculture production, catering, and to organise additional events (like the Slow Food Soweto EatIns). Local experts juxtaposed next to scientific experts makes knowledge accessible (often in the vernacular) for activism or enterprise development; and,

- The yearly schedule for the Lab was in the past developed through an end or beginning of the year participatory planning session. Speakers proved impossible to secure, but the announcement hour themes are often suggested for future events. This indicates the Lab can respond flexibly to new and pressing concerns as they emerge.

The above structure can be adapted to any open participatory event to allow the implementation of pertinent participatory methodologies, and in turn, to focus on a particular issue as it appears in the nexus. If a lab allows some to act, led by a sustainability narrative and within a pluralism that off-sets powerful interests, we need to understand how this allows actors to form their own networks and how these can promote sustainability.

\section{NETWORKS}

Asynchronous social media leaves a digital record of proceedings that is valuable for independent organising. Social media and its viral character, in the form of WhatsApp groups, groups on Facebook, groups on aparate.co, and groups and "members" on the iZindabazokudla.com website allow independent organising by actors themselves. The author exemplifies this, and has started developing training materials on another platform, the Start Up Tribe (https://www.thestartuptribe.org/courses/starta-farm). Companion pages have emerged that run alongside iZindaba Zokudla (see: https://iZindabazokudla.wordpress.com/; https://www.facebook.com/IZindabaZokudlaPage). This creates a pluralism, and this promotes people's own autonomy outside the Lab. This allows them to construct enterprises with multiple solidarities inside, and outside the Lab.

iZindaba Zokudla avoids using "inscription devices" in a hegemonic way. It keeps no records or "data" on participants except anonymous phone numbers (although the Facebook page and Website are open to analytics). Powerful actors have to use these open systems to recruit and mobilise entrepreneurs, offsetting their hegemony. The Lab has seen retailers commitin public - to specific prices for farmers (Malan, 2020c: 35), and several farmers are trading with this retailer. Participants in the lab has also exposed fraudsters who might want to exploit farmers for their own gain. A broad open ecosystem of interaction alongside such a Lab shows such progressive governance effects.

Communities are created so they can manage their own presence on social media and to choose their own groups and avenues for empowerment. This safe space stems from the "neutral" role of the university but also the subjective interaction amongst actors and stakeholders, which creates a contest amongst differing voices. This suggests a programme of stakeholder engagement, populated with information, opportunities, events, media, and technology, could affect how society will react and deliberate on the key challenges in sustainable governance.

\section{REFLECTION}

A public innovation lab creates opportunities in society to reflect and critically engage with governance. Reflection needs to be designed and operationalised, and social media affords us explicit opportunities in this regard. However, additional reflective opportunities are created by the narratives and frames that can be brought to such a lab, by the activities of leaders in such a context, and by effects a lab would have on actions taken in society. Actors use the material from such a lab to "infrastructure" their enterprises and also their immediate contexts to promote their interests and this is the driving force of sustainability. Sustainability needs to be framed as an explicit objective, and technical and other considerations subsumed under this narrative.

iZindaba Zokudla holds no official power, but its activities point to a critical alternative to mainstream agricultural development, that "homogenises" (often through "Master Plans") agriculture, whilst sustainability implies critical engagement with and the transformation of vested interests. iZindaba Zokudla's independence and its connexions to actors on the ground allows the creation of alternative means for agricultural development that can be institutionalised as an alternative to extension programmes. This will enable us to operationalise sustainability 
either through engagement, trial and error, or through the actions of others.

\section{CONCLUSION: GOVERNING THE SUBJECT FOR SUSTAINABILITY}

iZindaba Zokudla aims at progressive outcomes, and this serendipity of progressive outcomes may be due to its ability to infrastructure society or recreate the social contract. A public innovation lab that pluralises the governance of the nexus allows networks to complete the labour needed to realise sustainability. $\mathrm{A} \mathrm{Lab}$ as a process of engagement develops narratives that coordinates action amongst many and allows dedicated networks or communities to take action. A public innovation lab creates these opportunities and is suggestive of a new approach to social change that operationalises the volition of concerned and active groups in society, and makes them the drivers of sustainability.

\section{REFERENCES}

Battersby, J. (2012). Beyond the food desert: finding ways to speak about urban food security in South Africa. Geografiska Annal. Series B Hum. Geograph. 94, 141-159. doi: 10.1111/j.1468-0467.2012.00401.x

Battersby, J., Haysom, G., Marshak, M., Kroll, F., and Tawodzera, G. (2015). A Study on Current and Future Realities for Urban Food Security in South Africa. Johannesburg: South African Cities Network.

Broad-Based Black Economic Empowerment Act No. 25899 (2004). Retrieved from Government Gazette (Act No. 53 of 2003). Available online at: https://www.gov. $\mathrm{za} /$ sites/default/files/gcis_document/201409/a53-030.pdf

Bruton, G. D., Ketchen, D. J. Jr., and DuaneIreland, R. (2013). Entrepreneurship as a solution to poverty. J. Bus. Ventur. 28, 683-689. doi: 10.1016/j.jbusvent.2013.05.002

Burns, D. (2012). Participatory systemic inquiry. IDS Bull. 43, 88-100. doi: 10.1111/j.1759-5436.2012.00325.x

Campbell, A. D., and Malan, N. (2018). "iZindaba Zokudla (conversations about food): Innovation in the Soweto food system," in Public interest design education guidebook: Curricula, strategies, and SEED Academic Case Studies, eds L. M. Abendroth and B. Bell (New York, NY: Routledge), 158-164.

Candel, J. J. L. (2018). Diagnosing integrated food security strategies. NJAS-Wageningen J. Life Sci. 84, 103-113. doi: 10.1016/j.njas.2017. 07.001

Carlson, B., and Frazer, R. (2020). "They got filters": Indigenous social media, the settler gaze, and a politics of hope. Soc. Media Soc. 2020, 1-11. doi: $10.1177 / 2056305120925261$

Christian, A. J., Day, F., Diaz, M., and Peterson-Salahuddin, C. (2020). Platforming intersectionality: networked solidarity and the limits of corporate social media. Soc. Media Soc. 2020, 1-12. doi: 10.1177/20563051209 33301

Clayes, P. (2015). Human Rights and the Food Sovereignty Movement: Reclaiming Control. New York, NY: Routledge.

Cochet, H., Anseeuw, W., and Fréguin-Gresh, S. (2015). South Africa's Agrarian Question. Pretoria: HSRC Press.

Csortan, G., Ward, J., and Roetman, P. (2020). Productivity, resource efficiency and financial savings: an investigation of the current capabilities and potential of South Australian home food gardens. PLoS ONE 15:e0230232. doi: 10.1371/journal.pone.0230232

Flew, T. (2020). Social media governance. Soc. Media Soc. 2015, 1-2. doi: $10.1177 / 2056305115578136$

Gebreyes, M. (2018). Producing' institutions of climate change adaptation and food security in north eastern Ethiopia. NJAS-Wageningen J. Life Sci. 84, 123-132. doi: 10.1016/j.njas.2017.10.007

\section{DATA AVAILABILITY STATEMENT}

The datasets presented in this article are not readily available because the data has been be abstracted and anonymized to protect identities. Requests to access the datasets should be directed tonmalan@uj.ac.za.

\section{ETHICS STATEMENT}

Written informed consent was not obtained from the individual(s), nor the minor(s)' legal guardian/next of kin, for the publication of any potentially identifiable images or data included in this article.

\section{AUTHOR CONTRIBUTIONS}

The author confirms being the sole contributor of this work and has approved it for publication.

Hassan, Z. (2014). Towards a Theory of Systemic Action. Available online at: https://static1.squarespace.com/static/5eea166df25ed350848d72ce/ t/5ef4d22bf159c74e4e325df2/1593102892366/Towards_a_Theory_Of_ Systemic_Action_REV03.pdf

Haysom, G. (2015). food and the City: urban food system governance. Urban Forum. 26, 263-281. doi: 10.1007/s12132-015-9255-7

IoD (2016) King IV report on corporate governance for South Africa 2016. Sandton: Institute of Directors.

Jensen, P. D., and Orfila, C. (2021). Mapping the production-consumption gap of an urban food system: an empirical case study of food security and resilience. Food Secur. 21:142. doi: 10.1007/s12571-021-01142-2

Joubert, L., Battersby, J., and Watson, V. (2018). Tomatoes and Taxi Ranks: Running our Cities to fill the food gap. Cape Town: African Centre for Cities.

Lemke, L. (2002). Foucault, governmentality, and critique. Rethink. Marx. 14, 49-64 doi: 10.1080/089356902101242288

Lemke, T. (2000). 'The birth of biopolitics': Michel Foucault's lecture at the Collège de France on neo-liberal governmentality. Econ. Soc. 30, 190-207. doi: 10.1080/03085140120042271

Lemke, T. (2007). An indigestible meal? foucault, governmentality and state theory. Distinktion: J. Soc. Theory 8, 43-65. doi: 10.1080/1600910X.2007. 9672946

Lenton, T. M., and Latour, B. (2018). Gaia 2.0.: Could humans add some level of self-awareness to Earth's self-regulation? Science 361, 1066-1068. doi: $10.1126 /$ science.aau0427

Lynde, R. (2020). Innovation and entrepreneurship driving food system transformation. Physiol. Behav. 220, 112866-112870. doi: $10.1016 /$ j.physbeh.2020.112866

Mahajan, S. (2014). "Economics of South African townships: Special focus on Diepsloot," in World Bank Studies. Washington, D.C.: World Bank.

Malan, N. (2015). Urban farmers and urban agriculture in Johannesburg: Responding to the food resilience strategy, Agrekon 54, 51-75, doi: 10.1080/03031853.2015.1072997

Malan, N. (2020a). "Service learning and stakeholder action: technology and education for urban agriculture in Johannesburg, South Africa," in Urban Food Transitions in the Global North and South, ed A. Thornton (London: Palgrave Macmillan), 177-192.

Malan, N. (2020b). "Emerging enterprises and sustainability in the food system: Food entrepreneurs in South Africa," in Urban Food Transitions in the Global North and South, ed A. Thornton (London: Palgrave Macmillan), 193-212.

Malan, N. (2020c). iZindaba Zokudla: A conversation about food systems change in South Africa. JAFSCD. 10, 29-42. doi: 10.5304/jafscd.2020.101.016

Malan, N., and Campbell, A. D. (2014). "Design, social change and development: a social methodology," in Design with the Other 90\%: Changing the World 
by Design, eds A. Breytenbach and K. Pope (Johannesburg: Greenside Design Center and University of Johannesburg), 94-101. Available online at: https://www.cumulusassociation.org/design-with-the- other-90-cumulusjohannesburg-conference-proceedings/

Malan, N., and van der Walt, J. (2019). Building digital and real communities for change: The design of iZindaba Zokudla groups.

McGann, M., Blomkamp, E., and Lewis, J. M. (2018). The rise of public sector innovation labs: Experiments in design thinking for policy. Policy Sci. 51, 249-267. doi: 10.1007/s11077-018-9315-7

McGann, M., Wells, T., and Blomkamp, E. (2019). Innovation labs and coproduction in public problem solving. Public Manage. Rev. 23, 297-326. doi: 10.1080/14719037.2019.1699946

McMichael, P. (2014). Historicizing food sovereignty. J. Peasant Stud. 41, 933-957, doi: $10.1080 / 03066150.2013 .876999$

Minister of Public Works (2020). Republic of South Africa. Expropriation Bill Tshwane: Government Printer. Available online at: https://www.gov.za/sites/ default/files/gcis_document/201605/b4d2015pdf.pdf

Nogueira, A., Ashton, W., Teixeira, C., Lyon, E., and Pereira, J. (2020). Infrastructuring the circular economy. Energies 13:1805. doi: $10.3390 /$ en 13071805

Ostrom, E. (1990). Governing the Commons: The Evolution of Institutions for Collective Action. Cambridge: Cambridge University Press.

Pereira, L. M. (2014). The future of South Africa's food system: What is research telling us? SA Food Lab, South Africa.

Pereira, L. M. (2021). Imagining better futures using the seeds approach. Soc. Innov. J. 5:513.

Pereira, L. M., and Drimie, S. (2016). Governance arrangements for the future food system: addressing complexity in South Africa. Environ. Sci. Policy Sustain. Develop. 58, 18-31. doi: 10.1080/00139157.2016.1186438

Pereira, L. M., Drimie, S., Maciejewski, K., Tonissen, P. B., and Biggs, R. (2020). Food System transformation: integrating a political-economy and socialecological approach to regime shifts. Int. J. Environ. Res. Public Health 17:1313. doi: 10.3390/ijerph17041313

Pereira, L. M., Karpouzoglou, T., Doshi, S., and Frantzeskaki, N. (2015). Organising a safe space for navigating socialecological transformations to sustainability. Int. J. Environ. Res. Public Health 12, 6027-6044. doi: 10.3390/ijerph120606027

Regeer, B., Mager, S., and van Oorsouw, Y. (2011). License to Grow: Innovating Sustainable Development by Connecting Values: An Insight in the Connected Value Development Approach for Wicked Problems. Amsterdam: Vrije Universiteit Press.

REOS Partners, and TransForum (2011). Summit Report: 1st Global Summit on Metropolitan Agriculture. Available online at: https://Reospartners.com/wpcontent/uploads/old/SummitReport_17012011.pdf

Roosendaal, L., Herens, M., de Roo, N., Stuiver, M., Pittore, K., Soma, K., and Hetterscheid, B. (2020). City Region Food System Governance; Guiding Principles and Lessons Learned From Case Studies Around the World. Wageningen Centre for Development Innovation, Wageningen University and Research. Report WCDI-20-118. Wageningen.

Rousell, C. (2017). Seed Capture in South Africa: A Threat to Seed Freedom but the Seed Movement is Fighting Back. Available online at: https://acbio.org.za/ en/seed-capture-south-africa-threat-seed-freedom-seed-movement-fightingback
Sidibé, A., Totin, E., Thompson-Hall, M., Traoré, O. T., Traoré, P. C. S., and Olabisi, L. S. (2018). Multi-scale governance in agriculture systems: Interplay between national and local institutions around the production dimension of food security in Mali. NJAS-Wageningen J. Life Sci. 84, 94-102. doi: 10.1016/j.njas.2017.09.001

Siegner, A. B., Acey, C., and Sowerwine, J. (2020). Producing urban agroecology in the East Bay: from soil health to community empowerment. Agroecol. Sustain. Food Syst. 44, 566-593. doi: 10.1080/21683565.2019.1690615

Soriano, C. R. R., and Cabañes, J. V. A. (2020). Entrepreneurial solidarities: social media collectives and Filipino digital platform workers. Social Med. Soc. 2020, 1-11. doi: 10.1177/2056305120926484

Suchá, L., Schlossarek, M., Dušková, L., Malan, N., and Šarapatka, B. (2020). Land tenure security and its implicatins for investments to urban agriculture in Soweto, South Africa. Land Use Policy 97:104739. doi: 10.1016/j.landusepol.2020.104739

Termeer, C. J. A. M., Drimie, S., Ingram, J., Pereira, L. M., and Whittingham, M. J. (2018). A diagnostic framework for food system governance arrangem,ents: the case of South Africa. NJAS- Wageningen J. Life Sci. 84, 85-93. doi: 10.1016/j.njas.2017.08.001

Tobias, J. T., Mair, J., and Barbosa-Leiker, C. (2013). Towards a theory of transformative entrepreneuring: Poverty reduction and conflict resolution in Rwanda's entrepreneurial coffee sector. J. Bus. Ventur. 28, 728-742. doi: 10.1016/j.jbusvent.2013.03.003

Van der Ploeg, J. D. (2016). Theorizing agri-food economies. Agriculture 6:30. doi: 10.3390/agriculture6030030

Van Latesteijn, H., and Andeweg, K. (2011). The TransForum Model: Transforming Agro-Innovation Towards Sustainable Development. Dordrecht: Springer.

Wenger, E. (1998), Communities of Practice: Learning, Meaning and Identity. Cambridge: Cambridge University Press.

Williamson, B. (2015). 'Governing methods: policy innovation labs, design and data science in the digital governance of education'. J. Educ. Administr. Hist. 47, 251-271. doi: 10.1080/00220620.2015.1038693

World Commission on Environment and Development (1987). Report of the World Commission on Environment and Development: Our Common Future. Oxford: Oxford University Press.

Conflict of Interest: The author declares that the research was conducted in the absence of any commercial or financial relationships that could be construed as a potential conflict of interest.

Publisher's Note: All claims expressed in this article are solely those of the authors and do not necessarily represent those of their affiliated organizations, or those of the publisher, the editors and the reviewers. Any product that may be evaluated in this article, or claim that may be made by its manufacturer, is not guaranteed or endorsed by the publisher.

Copyright (๑) 2021 Malan. This is an open-access article distributed under the terms of the Creative Commons Attribution License (CC BY). The use, distribution or reproduction in other forums is permitted, provided the original author(s) and the copyright owner(s) are credited and that the original publication in this journal is cited, in accordance with accepted academic practice. No use, distribution or reproduction is permitted which does not comply with these terms. 